\title{
Prevalence of Smoking and the Related Factors Among the Elderly in Kashmar, Iran
}

\author{
Hashem Heshmati ${ }^{1, *}$; Abdurrahman Charkazi ${ }^{1}$; Rasoul Asnaashari ${ }^{1}$; Faramarz Koohsar ${ }^{2}$ \\ ${ }^{1}$ Department of Public Health, School of Health, Golestan University of Medical Sciences, Gorgan, IR Iran \\ ${ }^{2}$ Department of Laboratory Science, Faculty of Paramedical, Golestan University of Medical Sciences, Gorgan, IR Iran \\ *Corresponding author: Hashem Heshmati, Department of Public Health, School of Health, Golestan University of Medical Sciences, Gorgan, IR Iran. Tel: +98-9134512051, Fax: \\ +98-1714423630, E-mail: Heshmati.hashem@yahoo.com
}

Received: August 3, 2013; Revised: September 28, 2013; Accepted: October 4, 2013

Keywords: Smoking; Aged; Mortality

\section{Dear Editor,}

According to World Health Organization (WHO) report, there are 1.3 billion smokers in the world and smoking is responsible for approximately five million deaths all over the world every year (1). Smoking is a strong predictor of coronary heart disease (CHD) and mortality (2). The findings suggest that smoking might increase influenzaassociated mortality risks among elders (3). In addition, elderly smokers are at risk of obesity and diabetes (4). Moreover, it is associated with total tooth loss (5). Smoking is also a risk factor for cancer (6). According to WHO, 14.2\% of Iranian population, ranging between 15 and 64 are smokers (7). The current report is the result of the study with the aim of determinant prevalence of smoking and its related factors in the elderly in Kashmar, Iran, derived from a study conducted on aged population lifestyle.

In a cross sectional study carried out in 2011, 267 elderly people were selected by using stratified sampling method in Kashmar city, in the East of Iran. The samples were selected based on the number of the elderly covered under each health center. Data were obtained through interview by using a reliable and valid questionnaire. Data were analyzed by using SPSS software version 15 with Chi-square and Fisher exact tests. Mean age of under-studied elderly was $69.03 \pm 6.22$ and the age range was $60-87$ years old. $52.4 \%$ of the elderly were men and $2.6 \%$ of whom always smoked, $12.7 \%$ often, $9.4 \%$ sometimes, $14.6 \%$ rarely smoked and $60.7 \%$ of them never smoked. Smoking was significantly higher among men $(P=0.000)$, the elderly living alone $(P=0.038)$ and the elderly who had heart disease $(\mathrm{P}=0.026)$. There was no significant association between smoking with diabetes $(\mathrm{P}=0.227)$ and education level $(\mathrm{P}=0.178)$.
Prevalence of smoking in the under-studied population is higher than other parts of Iran $(8,9)$, even higher than other neighborhood countries such as Turkey (10) and Pakistan (11). In contrast to studies by Zhu et al. and Husten et al. $(12,13)$ that smoking prevalence had no significant association with education level, that of our study showed relevance to low level of education in our participants. Elderly living alone smoked more in comparison to others. Loneliness is likely to be associated with mental problems such as mood disorders. Other studies carried out in this area indicated that depression in elders could be aggregated by smoking $(14,15)$. In line with heart disease, heart disease could be influenced by smoking; however, smoking is the main cause or aggravator for heart disease. In conclusion, our survey revealed that smoking prevalence in Kashmar is higher than not only other parts of Iran but also the neighborhood countries. Hence, we recommend appropriate research to figure out what causes smoking prevalence to be higher in elderlies, especially among the male who live alone. Due to the small size of the sample for the current study, more investigation in other parts of the country is required to identify the smoking prevalence and its related factors as well as appropriate interventions such as educational intervention and advocacy to decrease the prevalence of smoking among the elderly.

\section{Acknowledgements}

The authors would like to thank the elderly of Kashmar city who took part in the study. 


\section{Authors' Contribution}

Study design, Hashem Heshmati; data collection, Rasoul Asnaashari; analysis and interpretation, Hashem Heshmati; drafting the manuscript, Hashem Heshmati and Abdurrahman Charkazi; revision, Faramarz Koohsar.

\section{Financial Disclosure}

There is no financial disclosure.

\section{Funding/Support}

There was no financial support.

\section{References}

1. WHO Report on the Global Tobacco Epidemic, 2009: Implementing smoke-free environments. WHO; 2009. [December 22, 2011]. Available from: http://www.who.int/tobacco/mpower/2009/en/.

2. Sulander T, Helakorpi S, Rahkonen O, Nissinen A, Uutela A. Smoking and alcohol consumption among the elderly: trends and associations, 1985-2001. Prev Med. 2004;39(2):413-8.

3. Wong CM, Yang L, Chan KP, Chan WM, Song L, Lai HK, et al. Cigarette smoking as a risk factor for influenza-associated mortality: evidence from an elderly cohort. Influenza Other Respir Viruses. 2013;7(4):531-9.

4. Sulander T, Rahkonen O, Nissinen A, Uutela A. Association of smoking status with obesity and diabetes among elderly people. Arch Gerontol Geriatr. 2007;45(2):159-67.

5. Hanioka T, Ojima M, Tanaka K, Aoyama H. Association of total tooth loss with smoking, drinking alcohol and nutrition in elderly Japanese: analysis of national database. Gerodontology.
2007;24(2):87-92.

6. Shopland DR, Eyre HJ, Pechacek TF. Smoking-attributable cancer mortality in 1991: is lung cancer now the leading cause of death among smokers in the United States? J Natl Cancer Inst. 1991;83(16):1142-8.

7. WHO Report on the Global Tobacco Epidemic, 2008 - The MPOWER package. WHO; 2008. Available from: http://www.who.int/tobacco/mpower/2008/en/.

8. Alavi Naieny AM, Dorosti Motlagh AR, Aghdak P. Survey of obesity, underweight and associated factors in elderly people, using some of anthropometric indices in Isfahan City, 2004. JMazandaran U Med Sci. 2006;16(52):117-23.

9. Azizi F, Emami H, Salehi P, Ghanbarian A, Mirmiran P, Mirbolooki M. Cardiovascular risk factors in the elderly: Tehran Lipid and Glucose Study (TLGS). Iran JEndocrinol Metab. 2003.

10. Ozkara A, Turgut F, Kanbay M, Selcoki Y, Akcay A. Populationbased cardiovascular risk factors in the elderly in Turkey: a crosssectional survey. Cent EurJ Med. 2008;3(2):173-8.

11. Ahmad K, Jafary F, Jehan I, Hatcher J, Khan AQ, Chaturvedi N, et al Prevalence and predictors of smoking in Pakistan: results of the National Health Survey of Pakistan. EurJ Cardiovasc Prev Rehabil. 2005;12(3):203-8.

12. Zhu BP, Giovino GA, Mowery PD, Eriksen MP. The relationship between cigarette smoking and education revisited: implications for categorizing persons' educational status. Am J Public Health. 1996;86(11):1582-9.

13. Husten CG, Shelton DM, Chrismon JH, Lin YC, Mowery P, Powell FA. Cigarette smoking and smoking cessation among older adults: United States, 1965-94. Tob Control. 1997;6(3):175-80.

14. Kim SK, Park JH, Lee JJ, Lee SB, Kim TH, Han JW, et al. Smoking in elderly Koreans: prevalence and factors associated with smoking cessation. Arch Gerontol Geriatr. 2013;56(1):214-9.

15. Kenney BA, Holahan CJ, Holahan CK, Brennan PL, Schutte KK Moos RH. Depressive symptoms, drinking problems, and smoking cessation in older smokers. Addict Behav. 20 09;34(6-7):548-53. 